\title{
JORNALISMO, ASSESSORIA DE IMPRENSA E SEUS CONDICIONANTES ORGANIZACIONAIS: UMA REFLEXÃO A PARTIR DAS TEORIAS DO JORNALISMO
}

\author{
JOURNALISTS, PRESS OFFICERS AND THEIR ORGANIZATIONAL \\ CONSTRAINTS: A DISCUSSION FROM THE THEORIES OF JOURNALISM
}

\author{
PERIODISMO, ASESORÍA DE PRENSA Y SUS CONDICIONANTES \\ ORGANIZATIVAS: UNA REFLEXIÓN A PARTIR DE \\ LAS TEORÍAS DEL PERIODISMO
}

\author{
Francisco Paulo Jamil Almeida Marques \\ Doutor, UFC \\ marquesjamil@gmail.com \\ Edna Miola \\ Doutora, UFPS \\ ednamiola@gmail.com \\ Nayana Siebra \\ Jornalista \\ nayanasiebra@gmail.com
}

\begin{abstract}
Resumo
O trabalho reflete, a partir de uma abordagem ensaística, sobre os quadros de referência deontológicos típicos de duas atividades da área de Comunicação: o Jornalismo e a Assessoria de Imprensa. Em primeiro lugar, são discutidas as singularidades que marcam as atividades cotidianas de jornalistas e de assessores especificamente no caso brasileiro. Em seguida, o texto analisa as características da Teoria Organizacional, dedicada a compreender os constrangimentos que as empresas impõem aos produtores de informação. A partir da literatura e da verificação de um conjunto de ilustrações, conclui-se haver uma tensão permanente entre jornalistas e assessores. A atuação de ambos os profissionais, porém, encontra-se fortemente subsumida à orientação de seus empregadores.
\end{abstract}

Palavras-chave: Jornalismo. Assessoria de Imprensa. Deontologia.

\begin{abstract}
The article examines the ethical frameworks of two important activities of the Communication field: Journalism and Public Relations (regarding the press officers' work in the Brazilian case). First, one discusses the singularities of each activity. Next, we examine the characteristics of the Organizational Theory, dedicated to understanding the constraints that organizations impose on the producers of information. We conclude that in Brazil there is a constant tension between journalists and press officers. The performance of both professionals, however, is strongly subsumed under the guidance of their employers.
\end{abstract}


Keywords: Journalism. Public Relations. Ethics.

\section{Resumen}

El artículo examina los cuadros de referencia deontológicos típicos del Periodismo y de la Asesoría de Prensa. El texto analiza las características de la Teoría de las Organizaciones, dedicada a comprender los constreñimientos que las empresas imponen a los productores de información. A partir de la literatura y de la verificación de un conjunto de ilustraciones, se concluye haber una tensión permanente entre periodistas y asesores. La actuación de ambos los profesionales, sin embargo, se encuentra fuertemente subsumida a la orientación de sus empleadores.

Palabras clave: Periodismo. Asesoría de Prensa. Deontología.

\section{A CONSTRUÇÃO DO CAMPO DO JORNALISMO: PRINCÍPIOS, VALORES E AGENTES}

Uma explicação apropriada sobre a atividade de produzir e de distribuir notícias depende de certas considerações a respeito da diferenciação social pela qual passou o campo do Jornalismo ao longo dos últimos séculos (ALEXANDER, 1988; GOMES, 2009; HABERMAS, 1984; SCHUDSON, 2003).

Pode-se dizer que, em um primeiro momento, nomeadamente entre os séculos XVI e XVIII, a imprensa - entendida estritamente enquanto tecnologia de edição e impressão serviu para contestar os valores políticos e religiosos então vigentes. As manifestações e revoluções empreendidas pela classe burguesa - detentora de poder econômico, mas com escasso poder político - beneficiaram-se da maior difusão de informações divergentes daquelas hegemônicas à época. A derrocada dos regimes absolutistas nos principais países do continente europeu permitiu constatar o papel transformador da comunicação social.

Uma vez estabelecida a democracia representativa (mais exatamente entre os séculos XVIII e XIX), a tecnologia de impressão assumiu, como uma de suas funções, o caráter de tribuna dos interesses dos partidos políticos - agora dedicados não à derrubada do regime vigente, mas ao favorecimento da concorrência para que os representantes obtivessem maior adesão do conjunto de eleitores (MANIN, 1997; MARQUES, 2008). Assim como ocorre hoje em dia, tornou-se comum a instrumentalização da comunicação por parte de determinadas agremiações com o intuito de divulgar suas perspectivas de mundo e programas de governo. Os partidos investiam na sustentação financeira de tais periódicos atentando para uma perspectiva de lucro não necessariamente econômica, mas político-ideológica. 
A terceira fase da imprensa, denominada "comercial", tem início a partir do século XIX (ainda que experiências em períodos anteriores tenham sido testemunhadas); um de seus motes é a industrialização, que se espalhava com maior rapidez em parte da Europa. O barateamento nos custos de produção do maquinário e do papel permitiu a produção em larga escala de materiais impressos. O processo que transformou a informação em mercadoria acompanhou tal ritmo de inovação e abriu espaço para a emergência de uma nova atividade social, voltada para coletar, produzir e distribuir conteúdos a uma audiência que adquiria cada vez mais a capacidade de leitura.

Mas sabe-se que não basta produzir informação para que ela seja aceita em um mercado caracterizado por uma crescente concorrência. Nesse sentido, os jornais, ao contrário de instituições já consolidadas a exemplo dos partidos, precisavam construir uma imagem pública positiva para se sobressair no mercado de ideias. O produto jornalístico deveria apresentar um "diferencial de mercado" para ganhar espaço entre os diversos tipos de conteúdo já oferecidos à época. É por tal motivo que, ao longo do século XIX e durante boa parte do século XX, o esforço maior da atividade jornalística foi tornar o campo socialmente legítimo.

Para agregar valor à informação que ofereciam, os jornais precisaram, dentre outras medidas, provar que não cultivavam vínculos com agentes do campo político. A independência - além de passo essencial para a construção da credibilidade, por permitir ao jornal reivindicar qualidades como imparcialidade, neutralidade e defesa real do interesse público - atraía um público mais amplo, que não mais precisaria se dividir entre publicações patrocinadas por partidos. A maior variedade temática - com a criação de cadernos especializados - colaborou para consolidar o espaço do jornalismo comercial.

Destaque-se, contudo, que tal independência tinha como fiadora o patrocínio de empresas interessadas na atenção da audiência. A Publicidade e a Propaganda se desenvolveram de modo paralelo ao Jornalismo - que sempre teve na visibilidade seu capital fundamental, a ser barganhado com os outros campos sociais (BOURDIEU, 2006). A fim de assegurar ao leitor que não haveria interferência dos anunciantes na confecção dos materiais jornalísticos, separou-se a redação, de um lado, e o setor comercial, de outro (ainda que, até hoje, isso não tenha garantido uma completa isenção; mesmo indiretamente, verifica-se a intromissão do departamento comercial quando uma pauta é "derrubada" a fim de dar espaço a um anúncio de última hora).

Outra providência se referiu ao desenvolvimento de estratégias específicas. A separação entre notícia e opinião; a configuração do lead enquanto fórmula dedicada a 
contemplar o esforço por objetividade; a adoção da fotografia para passar a ideia de que seria possível "refletir a realidade" e o desenvolvimento de técnicas de entrevistas (uso de aspas, apelo a documentos produzidos por atores independentes): todo esse conjunto de estratégias acabou dando ao Jornalismo a prerrogativa de, em nome do público, questionar, por exemplo, autoridades legitimamente eleitas (ERBOLATO, 1979; LAGE, 1985; KOVACH e ROSENSTIEL, 2004; TRAQUINA, 2005). A utilização de termos como "quarto poder" ou "cão de guarda" tem origem exatamente em tal posicionamento que o campo passou a reclamar para si (ALBUQUERQUE, 2009; WAISBORD, 2000).

Uma vez que a atividade tenha se revestido de legitimidade, a diferenciação de mercado passou a ser buscada pelas empresas que integravam o campo. A concorrência entre os jornais fez com que tais instituições acirrassem a disputa por leitores, oferecendo desde simples comodidades (entregas dos exemplares em domicílio, promoções, criação de clubes de assinantes, caderno de anúncios classificados) até a adoção de refinados padrões de produção (manuais de redação, ombudsman, conselho de leitores, publicação de uma seção de erros etc.).

Um ponto também crucial no processo de legitimação e aquisição de credibilidade dos jornais passou, ainda, pelo perfil do profissional responsável pela elaboração das informações. Se, de início, o Jornalismo era profissão de indivíduos que não obtiveram sucesso em sua área de trabalho original e haviam adotado a tarefa apenas momentaneamente - o que provocava, dentre outras consequências, um rebaixamento dos salários -, aos poucos, a criação de associações, a adoção de códigos deontológicos (CHRISTOFOLETTI, 2011; KARAM, 2004) e o surgimento de cursos universitários consagraram o treinamento na área como fator adicional a atestar a qualidade dos conteúdos (TRAQUINA, 2005).

É verdade que, em alguns países, o diploma de formação superior na área também foi peça fundamental na orquestração da credibilidade (seria uma espécie de certificado do compromisso do profissional com produção noticiosa balizada em critérios transparentes). Mas, hoje em dia, tal exigência se mostra uma exceção na maioria dos países ocidentais (ALBUQUERQUE, 2009 e 2012).

A trajetória da atividade jornalística comprova que, aos poucos, foi-se formando um campo autônomo, compreendido pelas empresas e por seus profissionais. Os valores e princípios do trabalho concernente à produção noticiosa (isenção, honestidade, verdade, atualização, objetividade e outros) também se estruturaram a fim de distinguir o produto oferecido e de funcionar enquanto fonte de prestígio aos que ocupam posições na área. 
A independência do campo do Jornalismo visa, no final das contas, enfatizar o compromisso de seus integrantes com o interesse público, garantindo um espaço de exclusividade para determinadas abordagens sobre temas de relevância social. Essa noção de "capital" detido por profissionais e empresas do Jornalismo se mostra importante na medida em que, de forma análoga ao que acontece em outros campos, os agentes envolvidos com o processo de produção da notícia tentam, por vezes, transferir o prestígio obtido nessa função para outras atividades, a exemplo da Assessoria de Imprensa ou do campo da política.

A partir do estudo de uma das mais exploradas vertentes das Teorias do Jornalismo, a chamada "Teoria Organizacional", o trabalho reflete sobre o papel dos profissionais, de um lado, e das organizações, de outro, no processo de construção das informações.

Da mesma maneira que o jornalista, o assessor de imprensa produz conteúdos com objetivos específicos e se encontra submetido a lógicas organizacionais muitas vezes alheias às suas perspectivas próprias de mundo. Porém, acredita-se que, a depender da orientação e do interesse das instituições ou personalidades para as quais os assessores de imprensa prestam serviço, a atividade de comunicação de tal profissional adota princípios distintos daquela desempenhada pelo jornalista.

Assim, o trabalho reflete, a partir de uma abordagem ensaística, sobre os quadros de referência deontológicos típicos de duas atividades da área de Comunicação: o Jornalismo e a Assessoria de Imprensa. Em primeiro lugar, são discutidas as atividades do jornalista e do assessor de imprensa especificamente no caso brasileiro. Em seguida, o texto analisa as características da Teoria Organizacional com o intuito de explicar a submissão das lógicas profissionais aos interesses das instituições.

\section{AS POLÊMICAS FRONTEIRAS ENTRE JORNALISMO E ASSESSORIA DE IMPRENSA}

Os primeiros registros da atividade de Assessoria de Imprensa (AI) datam de 1906, nos Estados Unidos, quando Ivy Lee - que até então atuava no Jornalismo - decidiu montar um escritório voltado para trabalhar a imagem pública de determinados agentes e personalidades da época, a exemplo do empresário John Rockefeller Jr., tendo em vista a noção de que a imagem se referia ao conjunto de atributos que o público associava a alguém ou a alguma instituição (CHAPARRO, 2002; GOMES, 2004; WEBER, 2000). No Brasil, a demanda por profissionais com competências técnicas específicas dentro do campo da Comunicação foi consequência de uma série de fatores a exemplo do crescimento econômico, da industrialização e da urbanização do país (MAFEI, 2004). 
Do ponto de vista político, o processo de redemocratização do país ocorrido na década de 1980 acentuou a necessidade não apenas de se trabalhar a construção de visões de mundo por meio da instrumentalização dos media (estratégia recorrente do Regime Militar), mas, também, de convencer o público sobre a legitimidade de determinado representante, instituição ou argumento (ADGHIRNI, 2004, p. 4).

Nesse sentido, o assessor de imprensa pode ser definido como aquele profissional que administra a imagem de um determinado agente, atentando, por exemplo, para a forma através da qual os atos do assessorado serão cobertos ou oferecendo conselhos acerca de como reagir a determinada cobertura.

O fato é que, no Brasil, o assessor de imprensa, em boa parte das ocasiões, possui formação e experiência não na área de Relações Públicas, mas, sim, em Jornalismo. Esse perfil permite a tal profissional vantagens importantes: compreender bem o funcionamento das empresas do ramo noticioso; manter contato próximo com jornalistas e editores; conhecer os horários de fechamento das edições; obedecer a rotinas de produção; reconhecer demais detalhes que acabam contribuindo para uma promoção eficaz do assessorado (MAIA, 2008, p. 108).

A formação comum dos profissionais do Jornalismo e da AI costuma ser o centro de polêmicas. Fundadas em tal sobreposição, as associações de classe de jornalistas, a exemplo da Federação Nacional dos Jornalistas (FENAJ), se esforçam em reservar o espaço dos seus afiliados no mercado de Assessoria - por sinal, o ramo que emprega grande parte dos egressos das universidades.

Com o objetivo de defender esse posicionamento, bem como sistematizar nacionalmente o trabalho dos assessores, a FENAJ lançou, em 1985, um Manual de Assessoria de Imprensa. No referido documento, que já está em sua quarta edição, a entidade explica o seguinte:

Diante de tantas mudanças, empresas públicas e privadas não podem mais permanecer na penumbra, sem prestar contas de seus atos aos cidadãos brasileiros. E é nesse contexto que o jornalista que atua em Assessoria de Imprensa passa a exercer um papel essencial, pois é ele o profissional capacitado a preencher as lacunas entre os poderes públicos, a iniciativa privada e o terceiro setor com os meios de comunicação e, conseqüentemente com a própria sociedade (FEDERAÇÃO..., 2007b, p. 5).

Para a FENAJ, as funções do assessor de imprensa abrangem desde a manutenção de um bom relacionamento com jornalistas e gatekeepers até a organização do mailing e do clipping de notícias, estratégia tradicional de monitoramento daquilo que é publicado na área 
de interesse do assessorado ${ }^{1}$. Podem também ser arroladas na lista de tarefas do assessor a elaboração de releases; a organização e divulgação de eventos (coletivas de imprensa); a publicação de dados do interesse daquele que é atendido pelo profissional; e o acompanhamento do assessorado em entrevistas (FEDERAÇÃO..., 2007b, p. 8; MAFEI, 2004).

Em sintonia com a FENAJ, há estudiosos a argumentarem que a produção de informações a respeito das pessoas ou empresas que empregam os serviços de AI viria ao encontro das necessidades do próprio campo do Jornalismo.

As assessorias de imprensa, internas ou terceirizadas, devem ser verdadeiras produtoras de notícias, de artigos, de fundo capazes de promover a reflexão sobre as questões nacionais e mundiais, além de pautas que possam contribuir para a missão de informar. Missão essa importante e bem-vinda, pois os veículos de comunicação e agências de notícia, por maiores que sejam, não podem mobilizar um repórter em cada empresa, organização ou instituição que tenham informações de interesse da comunidade (CARVALHO e VIVEIROS, 2007, p. 45).

Em outras palavras, destaca-se a importância da Assessoria como facilitadora da própria atividade jornalística, afirmando que os assessores de imprensa permitem, por exemplo, que a fonte possa adicionar à cobertura noticiosa informações que, de outro modo, poderiam ser omitidas ou não chegariam ao conhecimento da audiência. É o que defendem Sartor e Baldissera:

[...] pode-se compreender por que o assessor torna-se mais importante para $o$ jornalista na medida em que atua como facilitador ou coprodutor da notícia, reduzindo o tempo e o esforço dedicados à apuração de dados ou à produção de uma matéria/reportagem. Vale notar, ainda, que o assessor tende a atuar desse modo por razões estratégicas, isto é, ao ser tomado como "parceiro" do jornalista, ao angariar sua simpatia, tem mais chances de ampliar a visibilidade de seu assessorado (SARTOR e BALDISSERA, 2011, p. 10).

Nesse sentido, parte dos jornalistas e de suas entidades representativas passaram a considerar a atuação em AI como um mercado a ser conquistado, expandido e preservado, já que, nas redações, não mais havia espaço para absorver a quantidade crescente de profissionais formados pelas universidades. Uma vez alcançado o sucesso em criar tal nicho

\footnotetext{
${ }^{1}$ Do ponto de vista da regulamentação da atividade, o Manual de Assessoria de Comunicação da FENAJ (2007b), ao examinar o Decreto número 83.284, de 13 de março de 1979, afirma o seguinte: "Ainda que a legislação, à época, não fizesse menção ao termo assessoria de imprensa, a descrição das funções [que são] de exercício privativo dos jornalistas profissionais [...] não deixa dúvidas de que as rotinas do assessor de imprensa competem exclusivamente aos profissionais diplomados em jornalismo". Para uma discussão mais aprofundada do ponto de vista da regulamentação das atividades do jornalista, do assessor e do relações públicas, ver Di Bella (2011).
} 
de mercado, coube aos defensores dessa ideia apresentarem as justificativas para equiparar os assessores aos jornalistas, a despeito dos possíveis conflitos deontológicos resultantes desse intento.

As polêmicas são de, pelo menos, duas ordens: 1) A AI seria uma atividade pertinente apenas aos profissionais de Relações Públicas?; 2) Deve-se questionar a validade de um mesmo "código de ética" para as atividades jornalística e de assessoria?

Nos países europeus, o profissional formado em relações públicas é aquele responsável pelas atividades típicas de $\mathrm{AI}$ no Brasil ${ }^{2}$. Observar a grade curricular dos cursos de RP no país permite perceber que os alunos são treinados para lidarem com técnicas do Jornalismo, principalmente para que compreendam a gramática de produção desses profissionais. Mas reconhece-se que há uma especificidade, sobretudo no que concerne aos princípios e padrões de atuação daqueles que desempenham a atividade.

\subsection{A disputa entre interesses públicos e privados}

Um amplo conjunto de estudiosos da área de comunicação insiste na diferenciação dos princípios, funções sociais e objetivos que guiam as atividades de Jornalismo, de um lado, e AI, do outro.

O resultado do processo de diferenciação social do Jornalismo foi a defesa da noção de que a independência de interesses políticos e econômicos guia as atividades de seus profissionais. Nesse sentido, é oportuna a explicação de Gomes (2004, p. 56) a respeito do tema:

Como em qualquer campo social, no jornalismo a legitimidade se conquista. Essa conquista dependerá, por outro lado, da estrutura de distribuição daquele capital que produz reconhecimento no campo. Quanto mais forte for, em geral, um campo social, maior sua autonomia face a outros campos e maior o zelo na defesa dos seus valores e princípios de distribuição de capital.

A reserva de mercado profissional dos Assessores de Imprensa expõe que o capital acumulado pelos jornalistas atuando exclusivamente em jornais é transferido para uma atuação que se dá - por mais controvérsias que possam ser geradas - no âmbito das Relações Públicas. Em outras palavras, a expertise, os contatos, o domínio dos processos e os

\footnotetext{
${ }^{2}$ De acordo com Bruno Barros Barreira: "Praticamente em toda a Europa a assessoria é função de relaçõespúblicas. E mesmo nos países em que os bacharéis em Jornalismo trabalham em assessoria, estes profissionais ficam impedidos de atuar em redações ou de se apresentarem como jornalistas. No Brasil, o desenvolvimento desta atividade tomou contornos singulares em relação ao resto do mundo" (BARREIRA, 2006). Para mais detalhes sobre a comparação das atividades de Jornalistas, Relações Públicas e Assessores de Imprensa em diferentes países, ver Chinem (2003).
} 
conhecimentos adquiridos nas redações acompanham os profissionais e promovem uma distinção positiva quando estes migram para a atuação em AI.

Desta forma, se é verdade que o assessor facilita a vida do jornalista, também é verdade que os atritos entre esses profissionais são constantes - o que, de antemão, evidencia uma tensão nos objetivos de cada atividade.

No imaginário do jornalista, portanto, a Assessoria de Imprensa tende a ser útil quando se adapta aos seus interesses e objetivos, mas parece ser negativamente avaliada quando prioriza a defesa do assessorado em detrimento de certos princípios do jornalismo, como a imparcialidade e o livre acesso ou a livre circulação de informações (SARTOR e BALDISSERA, 2011, p. 12).

Ora, o assessor pode facilitar a apuração jornalística, marcar entrevistas rapidamente, enviar dados quando isso for solicitado, mas também vai recorrer ao jornalista para trazer a público determinado assunto ou para oferecer uma perspectiva favorável ao seu cliente, no caso de uma notícia indesejável.

De acordo com Eugenio Bucci, a falta de clareza entre as duas funções teria uma origem sindical:

Como, historicamente, muitos jornalistas profissionais foram migrando, aos poucos, para as assessorias de imprensa, os sindicatos de jornalistas passaram a ter, entre seus associados, contingentes cada vez maiores de assessores. Para não perderem filiados esses sindicatos começaram a representar, de uma vez só, uns e outros. Nasceu assim uma teoria corporativista segundo a qual tanto os repórteres como os assessores de imprensa praticam "jornalismo" (BUCCI, 2010).

Provavelmente, a distinção mais evidente entre as duas atividades se reflete, justamente, no Código de Ética dos Jornalistas Brasileiros (FEDERAÇÃO..., 2007). Sabe-se que os códigos deontológicos desempenham duas funções importantes: internamente, um documento dessa natureza serve para orientar os profissionais da área, estabelecendo punições e recompensas morais que a comunidade estabelece a fim de preservar as diretrizes que guiam uma execução apropriada do trabalho; externamente, os códigos funcionam como estratégias direcionadas a agregar credibilidade àqueles responsáveis por determinada atividade.

No caso do Código de Ética da FENAJ, parece haver uma contradição na medida em que o documento adota uma perspectiva confusa em relação aos critérios que seus profissionais devem seguir. Ao mencionar que "os jornalistas não podem admitir que ele [o acesso à informação] seja impedido por nenhum tipo de interesse" (FEDERAÇÃO..., 2007, Art. $2^{\circ}$ ), o Código parece desconhecer o fato de que o assessor de imprensa faz parte do instrumental utilizado pelo assessorado justamente a fim de construir uma imagem pública 
positiva. Cotejar perspectivas de mundo diferentes, ouvindo fontes contraditórias ou concorrentes, por exemplo, não necessariamente faz parte do horizonte de trabalho do assessor.

Um jornalista que não preserva distanciamento da fonte tem seu trabalho comprometido. Receber presentes de alguém interessado na publicação de determinado material é algo impedido, como argumenta Bucci (2000), não pelo caráter individual, mas pela posição em que se encontra o jornalista - que está associado ao papel de fiscalizador. Por qual motivo um relacionamento tão próximo com uma empresa, um artista, ou um político não seria um problema para o assessor de imprensa?

\begin{abstract}
A aparência aqui é quase tudo. A independência e a integridade do jornalista, como as dos órgãos de imprensa, precisam ser mais que verdadeiras: precisam ser explícitas. Torná-las explícitas não é exibicionismo, é respeitar o público. Que não pairem dúvidas. Aliás, a independência do jornalista só é verdadeira quando é escancaradamente explícita (BUCCI, 2000, p. 81).
\end{abstract}

Outro fato que comprova a diferença essencial entre as duas atividades se refere ao conjunto de conflitos percebidos no cotidiano entre jornalistas e assessores. Há ocasiões em que o assessor impede o acesso do jornalista a uma autoridade pública; naturalmente, às vezes, o jornalista faz questão de conversar apenas com o assessorado. Da parte dos assessores, verifica-se a insistência sobre os jornalistas para que uma pauta sugerida seja coberta, ou para que seja destacado determinado ângulo de um acontecimento.

Ao fazer uma ressalva explícita a particularidades cotidianas enfrentadas pelo assessor em seu trabalho, o Código de Ética dos Jornalistas Brasileiros acaba por admitir que as duas atividades têm caráter diferente, como se verifica no trecho citado a seguir.

Art. 12. O jornalista deve: I - ressalvadas as especificidades da assessoria de imprensa, ouvir sempre, antes da divulgação dos fatos, o maior número de pessoas e instituições envolvidas em uma cobertura jornalística, principalmente aquelas que são objeto de acusações não suficientemente demonstradas ou verificadas (...) (FEDERAÇÃO..., 2007, grifo nosso).

Até aqui, discutiu-se uma série de questões que expõem as controversas compreensões das atividades de jornalistas e assessores de imprensa. Falou-se do processo de diferenciação social que legitimou o campo do Jornalismo e das condições de atuação profissional limitadas pelo mercado; discutiram-se algumas das incongruências que marcam os códigos de ética profissionais. Cabem, ainda, algumas considerações adicionais sobre as clivagens identificáveis na atuação dos jornalistas e assessores no que tange a alguns valores tais como interesse público, liberdade de imprensa e a reflexão sobre as práticas. 


\subsection{Jornalismo e Assessoria de Imprensa: Duas atividades diferentes?}

A pluralização dos suportes mediáticos tornou mais complexa não apenas a operação técnica dos diversos aparatos (exigindo treinamento por parte de profissionais), mas abriu espaço para que diferentes profissões dentro do campo da comunicação emergissem.

Os trabalhadores da área (jornalistas, radialistas, publicitários, designers, cineastas, relações públicas) foram treinados para produzir - com objetivos e a partir de parâmetros peculiares - informações de naturezas diversas. A questão, assim, passa a ser o exame dos condicionantes e das rotinas que afetam a produção de cada um deles. Ou seja, a que interesses atende a informação produzida e publicada? Não se ignora que, assim como o assessor, o jornalista participa da construção da notícia; a questão é refletir acerca dos limites de tal participação.

Algumas questões pertinentes a tal reflexão incluem: como é possível comprovar, na prática, a alegação do Jornalismo de que suas instituições e atores representam o interesse público? Que autoridade possuem os jornalistas para definir tal interesse? E que riscos analíticos traz a redução das diversas perspectivas sociais sob a palavra "público"? (MIGUEL, 2002; MIOLA, 2012; SILVA, 2006).

É legítimo indagar acerca, por exemplo, da liberdade de expressão e do compromisso que jornalistas e empresas da área mantêm com o interesse público. Ainda que, de certa forma, tenham sido superadas as querelas filosóficas acerca da possibilidade de existir objetividade no Jornalismo (BARROS FILHO, 1995; LIMA, 2008), permanecem as inquietações relativas à possibilidade dos jornalistas realizarem sua função pública de maneira independente.

(...) a liberdade de imprensa só é usada pelos donos das empresas. Em quarenta anos de jornalismo nunca vi liberdade de imprensa. Ela só é possível para os donos do jornal. Os jornalistas não podem ter opinião, mas os jornais têm suas opiniões sobre as coisas, que estão presentes nos editoriais e nos textos das pessoas que escrevem por linhas paralelas às do jornal. (ABRAMO, 1988, p. 116).

A fim de evitar esse tipo de problema, considera-se válida a insistente cobrança para que sejam aperfeiçoados métodos que promovam uma separação mais nítida entre redação e setor comercial. Ou seja, as injunções dos anunciantes devem ser evitadas a todo custo. Contudo, mesmo o método normativo "Igreja-Estado" (BUCCI, 2000) não resolve o problema descrito: as pressões das circunstâncias atingem cotidianamente o serviço do repórter. Assim, a depender do contexto, o Jornalismo pode ser visto com suspeição. Mas, 
ora, quem haveria de negar que, no caso da AI, tais pressões se manifestam de forma mais aguda?

Se há empresas que investem na adoção de manuais de redação ou que admitem publicamente seus erros, que exemplos os assessores de imprensa têm oferecido nesse mesmo sentido? O jornalista tem sua imagem comprometida caso seja surpreendido cometendo um erro de apuração: é testado e criticado pelo público se não cumpre sua tarefa de modo a contemplar o interesse coletivo. No campo da assessoria, não parece haver a mesma expectativa - o que é algo natural, já que não há correspondente, na relação entre assessor e audiência, ao pacto fiduciário que é estabelecido entre os agentes do Jornalismo e o seu público.

A situação se apresenta ainda mais complexa quando se percebe que os profissionais que desempenham essas atividades são colocados cotidianamente entre a defesa do interesse público - promovendo a transparência sobre a administração da coisa pública - e a demanda por proteger os interesses daqueles que os empregam. Em sua investigação sobre a Rede Brasileira de Comunicação Pública, Benetti e Moreira (2005) coletaram depoimentos de dezenas de jornalistas que, ao desempenhar suas funções de assessores de imprensa, veem-se pressionados por chefias e pela própria instituição do Estado que os contratou.

Ademais, tratando-se de órgãos da esfera governamental, o fato de que o salário dos assessores é pago com recursos públicos torna mais grave qualquer tentativa de instrumentalização da AI, principalmente quando a intenção é promover a imagem do chefe da instituição, e não do serviço prestado pelo órgão.

Não se quer afirmar, com isso, que as situações acima discutidas são indícios de que a AI tem por objetivo distorcer os fatos ou prejudicar o interesse público. Na realidade, deve-se compreender que fatores organizacionais - que já se reconhecem importantes para condicionar o trabalho nas redações - podem oferecer explicações também para se entender a dinâmica da AI.

Sendo assim, nem os profissionais da informação, nem as organizações para as quais eles prestam serviço podem ser pensados de maneira isolada. É o que argumenta a seção a seguir.

\section{DA INFLUENCIA DAS ORGANIZAÇÕES SOBRE A PRODUÇÃO DE INFORMAÇÕES}

A autoridade de um campo social é construída, dentre outros aspectos, a partir de elementos tais como o conhecimento técnico especializado detido pelos que atuam na área. $\mathrm{A}$ 
exigência de uma formação superior pertinente, a regulamentação da profissão por parte do Estado e a consolidação de um corpo específico de objetos, teorias e métodos colaboram para que determinada atividade ganhe destaque.

Mais recentemente, podem ser testemunhadas tentativas de afirmação de um campo do conhecimento na área do Jornalismo. As chamadas "Teorias do Jornalismo" consistem em um conjunto de sistematizações teórico-metodológicas a examinarem os fatores atinentes à produção, à distribuição, ao consumo e aos efeitos das notícias. Duas dessas teorias são essenciais para a compreensão da hierarquia que subordina os profissionais ao longo do processo de produção de conteúdos: a Teoria do Espelho e a Teoria Organizacional.

A Teoria do Espelho, cujo argumento está ligado à ideia de que as notícias são como são porque a realidade assim as determina, surgiu no final do século XIX, sob nítida influência positivista. Apega-se à ideologia dos jornalistas e das instituições do Jornalismo de que esses agentes se limitariam a divulgar efetivamente aquilo que ocorre, ocultando-se o papel do mediador. Os jornalistas seriam, nessa perspectiva, observadores imparciais e neutros que apenas relatariam os acontecimentos tais como eles se apresentam; trata-se de uma comunidade de desinteressados, responsáveis por reportar, objetivamente, os acontecimentos (CORREIA, 2011).

As críticas mais recorrentes a tal abordagem teórica expõem sua compreensão limitada sobre o papel desempenhado pelo Jornalismo na própria construção da realidade social (CORREIA, 2011; TRAQUINA, 2005). De acordo com a analogia de Felipe Pena (2005), na maioria das ocasiões, o jornalista refrata ou, simplesmente, descarta as sugestões de pauta que chegam às redações. Isso significa que o Jornalismo tem a função singular de oferecer à audiência um modo de ver e de organizar o que acontece no mundo; para isso, seleciona, edita, privilegia, enquadra, influenciando e sendo influenciado por fatores culturalmente vigentes (COSTA, 2009).

As Teorias do Jornalismo formuladas posteriormente se dedicaram a examinar especificamente o papel de diferentes dimensões e agentes no processo produtivo das notícias: foram estudadas desde a influência do pauteiro (gatekeeper) até a intromissão de interesses político-econômicos essencialmente externos ao campo do Jornalismo (Teorias de Ação Política), passando pelos efeitos que as notícias geram sobre a audiência (Agendamento, Framing, Espiral do Silêncio, Efeitos de Terceira Pessoa) (BARROS FILHO, 1995; CORREIA, 2011; TRAQUINA, 2005; PENA, 2005). A esta altura, já se percebe que muitas dessas sistematizações são, na maioria das vezes, complementares, em vez de contraditórias. Por isso, sem perder de vista a necessidade de enxergar o Jornalismo como uma atividade 
essencialmente complexa, o trabalho se debruça, a partir de agora, sobre a Teoria Organizacional.

As reflexões produzidas sob tal ponto de vista se concentram na investigação da influência dos fatores organizacionais sobre o processo de elaboração da notícia. Os princípios que marcam a Teoria Organizacional surgiram ainda na década de 1950, sendo Warren Breed um de seus autores fundamentais. De acordo com Nelson Traquina (2005, p. 152), no estudo intitulado Controle Social da Redação: Uma análise funcional, "Breed insere o jornalista no seu contexto mais imediato, a organização para a qual trabalha". Essa concepção defende que a produção das informações jornalísticas é determinada pela configuração (cultura e interesses) das instituições nas quais os profissionais atuam.

A Teoria Organizacional ressalta a importância da instituição, que tem o poder de submeter o jornalista às suas orientações. Para esta vertente, o jornalista faz o esforço de se adaptar às regras e normas editoriais da instituição. Traquina $(2005$, p. 153, itálicos no original) afirma que, em tal abordagem, "a ênfase está em um processo de socialização organizacional em que é sublinhada a importância duma cultura organizacional e não uma cultura profissional". Essa teoria torna explícita, assim, parte das várias dimensões da atividade jornalística ao distinguir a cultura da instituição, a cultura da profissão e a cultura (perfil individual) do próprio jornalista.

A adesão dos jornalistas às políticas editoriais das organizações noticiosas - o que caracterizaria o conformismo - é explicado por um conjunto de fatores. O primeiro deles se refere à autoridade institucional e às sanções que os profissionais podem sofrer caso não ajam de acordo com as regras da empresa. O jornalista se conforma com a política editorial porque reconhece o grau de superioridade dos veteranos na empresa, quando estes, por exemplo, determinam a distribuição de tarefas e pautas, escalam qual jornalista cobrirá que evento e indicam qual estrutura estará disponível para a tarefa. São também os agentes mais experientes aqueles responsáveis por editar o texto produzido pelos repórteres, por decidir pela publicação da autoria da matéria, bem como por sentenciar em que local (e com que prioridade) o conteúdo será veiculado. O conformismo com a política editorial seria justificado pelo receio dos jornalistas (sobretudo os mais jovens): contrariar seus superiores prejudicaria uma carreira ainda em construção (BREED, 1993).

O conformismo dos jornalistas seria também fruto "[d]os sentimentos de obrigação e [de] estima para com os superiores" (TRAQUINA, 2005, p. 154). Este fator lida não apenas com a questão concernente à hierarquia organizacional, mas, também, com uma perceptível gratidão que os jornalistas apresentariam em relação aos profissionais mais experientes ou aos 
editores que lhes deram a "chance" de publicar uma matéria de capa. "Vestir a camisa da empresa" (ou mesmo encarnar a ideia de "família" que determinadas chefias de redação querem plantar) pode fazer com que os profissionais sintam uma obrigação em relação a seus pares (BUCCI, 2000).

Destaque-se, também, a expectativa de ascensão profissional, o que incentiva profissionais a se mostrarem afinados com a linha editorial dos veículos. Tal comportamento seria um requisito para a continuidade e crescimento da carreira nas empresas. Percebe-se que o repórter também se esforça em atender as expectativas do público leitor que imagina para aquela publicação.

Por fim, o ritmo acelerado de produção da notícia submete os profissionais do Jornalismo à situação de estarem a todo o momento em busca de uma nova notícia, de um furo de reportagem. Um sistema sobrecarregado de produção da informação não concede tempo para que o jornalista reflita e confronte a linha editorial do veículo para o qual trabalha.

Destacar todos esses fenômenos que levam ao conformismo profissional não impede de se reconhecer que a atividade jornalística é caracterizada por certa autonomia profissional. Em outras palavras, a autoridade organizacional é apenas uma das dimensões que exercem influência na configuração final da notícia. Nesse sentido, Breed (1993) também apresentou, em seu trabalho, outros aspectos que contribuem para que o jornalista burle o controle exercido pela empresa.

Em primeiro lugar, o autor aponta a indefinição das políticas editoriais. Nem sempre o jornalista obedece ou se conforma com a política editorial pelo simples fato de tais códigos não serem claros ou completamente conhecidos por todos os integrantes da redação. Naturalmente, há ocasiões em que a própria empresa se beneficia de tal dubiedade: manter as normas editoriais imprecisas pode, de certa maneira, abrir margem para a autocensura por parte do repórter no momento da elaboração do texto.

Ademais, há de se creditar certa parcela de poder ao próprio jornalista, pois é ele quem apura a notícia, quem faz entrevistas e quem seleciona, em muitas ocasiões, os ângulos de cobertura. Nem sempre os editores e as chefias de redação têm conhecimento direto dos acontecimentos, uma vez que não vão com a mesma frequência a campo.

Finalmente, é essencial levar em conta a autonomia conquistada pelo profissional que já construiu um capital consolidado no campo: “os jornalistas empregados com o estatuto de estrela podem mais facilmente transgredir a política editorial” (TRAQUINA, 2005, p. 157).

A Teoria Organizacional, em suma, propõe que as notícias sejam interpretadas como resultado de um processo que habita a organização jornalística. O repórter sabe que seu 
trabalho está associado à função de seus superiores, sendo ele submetido à organização e às regras da empresa, e acaba agindo de acordo com a pequena, mas importante, margem de autonomia que lhe é concedida (CURRAN, 1990).

A reflexão apresentada toca em uma questão sensível: a autonomia do jornalista para tomar decisões face às exigências éticas, técnicas e mercadológicas. Defende-se que as demandas institucionais que as empresas de comunicação impõem aos jornalistas permitem fazer um paralelo entre o trabalho nas redações e a atividade das Assessorias de Imprensa.

Não se pode negar que o trabalho do assessor também é condicionado por aquele que o emprega. Dentre os constrangimentos próprios da AI, elenca-se, por exemplo, o receio de haver sanções à conduta dos profissionais; o esforço contínuo dos assessores por reconhecimento; as suas aspirações por desempenhar atividades mais bem remuneradas (tanto dentro quanto fora da empresa para a qual trabalham).

No desempenho de seu trabalho cotidiano, o assessor teme não possuir o domínio informativo dos fatos que deve divulgar (seu saber pode ser questionado por alguém de fora ou de dentro da instituição); busca ganhar confiança do empregador para, eventualmente, ter voz ao longo do processo de tomada de decisões na instituição. Em mais uma analogia, assim como o "furo" de reportagem atribui prestígio ao jornalista, a publicação na imprensa de um release enviado pelo assessor é a base do reconhecimento deste profissional ${ }^{3}$.

Ou seja, com os assessores de imprensa ocorre algo semelhante ao que atinge os jornalistas: nas assessorias, os profissionais também devem se ajustar à empresa para a qual trabalham. Acredita-se, contudo, que a margem de manobra do assessor tende a ser mais reduzida.

\section{DISCUSSÃO E CONCLUSÕES}

A naturalidade com a qual é vista a prática da assessoria por profissionais do jornalismo é problematizada na medida em que uma análise mais detida do Código de Ética dos Jornalistas Brasileiros permite diagnosticar possíveis conflitos de interesse; por isso, demanda-se cautela ao se afirmar a equivalência das duas profissões. A relação entre esses profissionais pode ser descrita em termos de aproximações e afastamentos, que se dão em função dos interesses que cada um deles defende.

\footnotetext{
${ }^{3}$ De acordo com Eugênio Bucci (2000, p. 80): “O assessor de imprensa se encarrega de intermediar as relações de seu cliente (ou patrão) com repórteres em geral, e sua eficiência é medida pela quantidade de reportagens favoráveis que saem publicadas - e pelas informações negativas que são omitidas".
} 
Sabe-se que as semelhanças entre as duas atividades não são poucas: além da imagem conquistada graças à formação na área de Jornalismo, o assessor utiliza técnicas da atividade. Ele sabe bem que obedecer às gramáticas do Jornalismo é crucial para obter sucesso na divulgação de um dado; um bom assessor deve compreender o melhor dia e horário para sugerir uma pauta. O Manual de Assessoria da FENAJ, por exemplo, enfatiza aquelas dimensões técnicas que permitiriam uma associação de tal atividade com o próprio cotidiano dos jornalistas (a produção de conteúdo informativo).

Por outro lado, cabe repensar se a contribuição mútua que ambos os profissionais podem oferecer os exime de observar a incompatibilidade de seus valores e códigos de ética. A tarefa de administrar imagens públicas, por exemplo, requer do assessor a habilidade de tomar certas decisões. É o caso de distinguir a quais informações se deve dar mais ênfase e, complementarmente, como se deve contornar, em caso de crise, a má repercussão das notícias. No final das contas, é o assessor de imprensa quem está em contato direto com as instituições jornalísticas, muitas vezes, lançando mão do capital adquirido por ele, em sua atuação nas redações.

Nesse sentido, parece razoável argumentar que o assessor de imprensa se aproxima mais de uma posição de fonte do que de um profissional dedicado a priorizar o interesse público. Esse é o argumento utilizado para se defender a ideia de que contratar um profissional que conhece a gramática de produção dos jornais seria um caminho mais curto no intuito de difundir visões de mundo de interesse dos clientes das assessorias. Isso não significa dizer que a assessoria implica omissão, mentira ou manipulação. Longe disso. Apenas quer-se ressaltar o fato de que, assim como as fontes, os assessores também gostariam de ver predominar visões de mundo que mais são convenientes para que seu trabalho seja reconhecido.

Uma dimensão geralmente omitida no debate sobre os princípios do Jornalismo e as tensões entre profissionais e estudiosos da área quando confrontados com a atividade de AI se refere ao papel das instituições quanto ao direcionamento do trabalho de quem lida com a informação. As organizações não podem ser pensadas de maneira isolada na medida em que moldam os campos de atuação e estabelecem diretrizes de trabalho.

É fundamental perceber que existe uma diferenciação na atividade jornalística, entre a cultura dos profissionais e a cultura da empresa nas quais eles desempenham seu trabalho. A análise do contexto e das margens de atuação dos assessores de imprensa, sob uma abordagem da Teoria Organizacional, oferece elementos para se construir um perfil acerca da atuação dos profissionais dedicados a administrar a imagem pública de empresas e indivíduos. 
Concorda-se com o argumento de que as duas profissões implicam funções e princípios diferentes; porém, é discutível o grau de independência dos jornalistas de redação frente às orientações das empresas.

A literatura a tratar os temas e polêmicas aqui discutidos ilustra como uma abordagem organizacional poderia contribuir para a pesquisa empírica sobre o cotidiano dessas duas atividades - o Jornalismo e a Assessoria de Imprensa - e sobre seus diferentes campos de atuação - as redações e as corporações. Investigar in loco os condicionantes que se impõem sobre o exercício profissional (especialmente, no campo das assessorias, não contempladas nos estudos sobre as rotinas produtivas do Jornalismo) poderia demonstrar em que medida coincidem ou se afastam os repertórios técnicos e deontológicos desses atores.

Para finalizar, aponta-se a necessidade de refletir sobre as consequências que a sobreposição de jornalistas e de assessores de imprensa traz para a própria imagem do

Jornalismo. É fundamental educar o cidadão, oferecendo-lhe subsídios para que exija uma informação com o máximo de exatidão e imparcialidade. Acredita-se, assim, que o debate entre as tensões geradas pelas atividades de Jornalismo e de Assessoria de Imprensa não se prendem somente ao âmbito profissional ou sindical e nem têm ligação somente com a dimensão empresarial: a esfera da cidadania é um agente interessado.

\section{REFERÊNCIAS}

ABRAMO, C. A regra do jogo: o jornalismo e a ética do marceneiro. São Paulo: Companhia das Letras, 1988.

ADGHIRNI, Z. L. O jornalismo entre a informação e a comunicação: como as assessorias de imprensa agendam a mídia. VII Colóquio Brasil-França de Ciências da Comunicação.

Anais... Porto Alegre: XXVII INTERCOM, 2004.

ALBUQUERQUE, A. On Models and Margins: Comparative media models viewed from a Brazilian perspective. In: HALLIN, D.; MANCINI, P. (eds.). Comparing Media Systems Beyond the Western World. Cambridge: Cambridge University Press, 2012. p. 72-95.

ALBUQUERQUE, A. As três faces do Quarto Poder. XVIII Encontro da COMPÓS. Anais..., Belo Horizonte, jun. 2009.

ALEXANDER, J. The mass media in systemic, historical, and comparative perspective. In: ALEXANDER, J. Action and its environment: toward a new synthesis. New York: Columbia University Press, 1988. p. 107-152. 
BARREIRA, B. B. Assessoria de Imprensa privativa de jornalistas, 2006. In: Observatório da Imprensa. Disponível em:

http://www.observatoriodaimprensa.com.br/news/view/assessoria-de-imprensa-privativa-dejornalistas. Acesso em 20 dez. 2013.

BARROS FILHO, C. Ética na Comunicação: da informação ao receptor. São Paulo: Moderna, 1995.

BOURDIEU, P. O poder simbólico. (9a ed.) Rio de Janeiro: Bertrand Brasil, 2006.

BREED, W. O controle social na redação. In: TRAQUINA, N. (org.). Jornalismo: questões, teorias e "estórias". Lisboa: Vega, 1993.

BUCCI, E. Sobre ética e imprensa. São Paulo: Companhia das Letras, 2000.

BUCCI, E. Diploma de Jornalismo: Assessor de imprensa é jornalista? Observatório da Imprensa, edição nº 606, 10 set. 2010.

CARVALHO, M. A.; VIVEIROS, R. O signo da verdade. São Paulo: Summus, 2007.

CHAPARRO, M. C. C. Cem Anos de Assessoria de Imprensa. In: DUARTE, J. (Org.). Assessoria de imprensa e relacionamento com a mídia. São Paulo: Atlas, 2002. p. 33-51.

CHINEM, Rivaldo. Assessoria de imprensa, como fazer? São Paulo: Summus, 2003.

CHRISTOFOLETTI, R. Por um sistema deontológico no jornalismo. Observatório da Imprensa, edição $n^{0}$ 730, 22 mar. 2011.

CORREIA, J. C. O admirável mundo das notícias: teorias e métodos. Covilhã: UBI/LabCom, 2011.

COSTA, C. T. Jornalismo como representação da representação: implicações éticas no campo da produção da informação. Líbero, São Paulo, v. 12, n. 23, jun. de 2009. p. 29-41.

CURRAN, J. Culturalist Perspectives of News Organizations: A Reappraisal and a Case Study. In: FERGUSON, M. (Ed.) Public Communication. London: Sage, 1990. pp.114-134.

DI BELLA, P. P. P. Jornalistas, Relações Públicas e Assessoria de Imprensa: Um problema de comunicação. Dissertação (Mestrado em Comunicação). Faculdade Cásper Líbero, São Paulo, 2011.

ERBOLATO, M. Técnicas de codificação em jornalismo. Petrópolis: Vozes, 1979.

FEDERAÇÃO Nacional dos Jornalistas. Código de ética dos jornalistas brasileiros.

Brasília: Federação Nacional dos Jornalistas, 2007. Disponível em:

$<$ http://www.fenaj.org.br/federacao/cometica/codigo_de etica_dos_jornalistas brasileiros.pdf $>$. Acesso em 23 jan. 2013.

FEDERAÇÃO Nacional dos Jornalistas. Manual de assessoria de comunicação. Brasília: Federação Nacional dos Jornalistas, 2007b. Disponível em: 
$<$ http://www.fenaj.org.br/mobicom/manual_de_assessoria_de_imprensa.pdf $>$. Acesso em 23 jan. 2013.

GOMES, W. Jornalismo, fatos e interesses. Florianópolis: Insular, 2009.

GOMES, W. Transformações da política na era da comunicação de massa. São Paulo: Paulus, 2004.

HABERMAS, J. Mudança estrutural da esfera pública. Rio de Janeiro: Edições Tempo Brasileiro, 1984.

INTERCOM. Enciclopédia INTERCOM de comunicação - Vol. 1: Dicionário Brasileiro do Conhecimento Comunicacional - Conceitos. São Paulo: Sociedade Brasileira de Estudos Interdisciplinares da Comunicação, 2010.

KARAM, F. Ética, deontologia, formação e profissão: observações sobre o Jornalismo. Estudos em Jornalismo e Mídia, Florianópolis, v. I n. 1, $1^{\circ}$ Semestre de 2004.

KOVACH, B.; ROSENSTIEL, T. Os elementos do jornalismo: o que os jornalistas devem saber e o público exigir. São Paulo: Geração Editorial, 2004.

LAGE, N. Estrutura da notícia. São Paulo: Ática, 1985.

LIMA, V. Entre a imparcialidade e o comprometimento. Observatório da Imprensa, edição $n^{\circ} 490,16$ jun. 2008.

MAFEI, M. Assessoria de imprensa: como se relacionar com a mídia. São Paulo: Contexto, 2004.

MAIA, R. C. M. (Coord.). Mídia e deliberação. Rio de Janeiro: Editora FGV, 2008.

MANIN, B. Principles of representative government. Cambridge: Cambridge University Press, 1997.

MARQUES, F. P. J. A. Participação política e internet: meios e oportunidades digitais de participação civil na democracia contemporânea, com um estudo do caso brasileiro. Tese (Doutorado em Comunicação e Cultura Contemporâneas). Universidade Federal da Bahia, Salvador, 2008.

MEDINA, C. Notícia, um produto a venda: jornalismo na sociedade urbana e industrial. 2.ed. São Paulo: Summus, 1988.

MIGUEL, L. F. Os meios de comunicação e a prática política. Lua Nova, $n^{0}$ 55-56, 2002. p. 155-184.

MIOLA, E. Sistema deliberativo e tensões entre interesses públicos e privados: a criação da Empresa Brasil de Comunicação em debate no Congresso e na imprensa. 294f. Tese (Doutorado em Comunicação Social). Faculdade de Filosofia e Ciências Humanas, Universidade Federal de Minas Gerais, Belo Horizonte, 2012. 
PARK, R. A notícia como forma de conhecimento: um capítulo dentro da sociologia do conhecimento. In: BERGER, C.; MAROCCO, B. (Org.). A era glacial do jornalismo: teorias sociais da imprensa. Porto Alegre: Sulina, 2008. v. 2. p. 51-70.

PENA, F. Teoria do jornalismo. São Paulo: Editora Contexto, 2005.

SARTOR, B.; BALDISSERA, R. Assessoria de Imprensa Imaginada. XXXII Congresso Brasileiro de Ciências da Comunicação. Anais... Curitiba, set. 2009.

SCHUDSON, M. Where News Came From: The History of Journalism. In: SCHUDSON, M. The Sociology of News. New York: Norton, 2003. p. 64-89.

SCROFERNEKER, C. M. A. Comunicando juntos... In: LOPES, B.; VIEIRA, R. F. Jornalismo e Relações Públicas: ação e reação. Rio de Janeiro: Mauad, 2004. p. 89-93.

SILVA, L. M. Jornalismo e interesse público. In: SEABRA, M. R.; SOUSA, V. (Org.). Jornalismo Político: Teoria, História e Técnicas. Rio de Janeiro: Record, 2006. p. 45-84.

TRAQUINA, N. Teorias do Jornalismo. Florianópolis: Insular, 2005.

WAISBORD, S. Watchdog Journalism in South America: News, Accountability and Democracy. New York: Columbia University Press, 2000.

WEBER, M. H. Comunicação e espetáculos da política. Porto Alegre, UFRGS, 2000.

Original recebido em: $31 / 05 / 2013$

Aceito para publicação em: 10/11/2013.

Resumo sobre os autores

Francisco Paulo Jamil Almeida Marques

Professor da Universidade Federal do Ceará. Pós-Doutor em Comunicação Social (UFMG). Doutor e Mestre em Comunicação e Cultura Contemporâneas (UFBA). Graduado em Jornalismo (UFC). Lider do Grupo de Pesquisa em Política e Novas Tecnologias (PONTE). Lattes: 


\section{Edna Miola}

Professora da Universidade Federal de Sergipe. É Doutora em Comunicação Social (UFMG), Mestre em Comunicação e Cultura Contemporâneas (UFBA) e Graduada em Comunicação Social/Publicidade e Propaganda (UFRGS). Lattes: http://lattes.cnpq.br/8089871576451243.

\section{Nayana Siebra}

Jornalista graduada pela Universidade Federal do Ceará. Atuou como bolsista de iniciação à docência no período em que contribuiu para a elaboração do trabalho.

Lattes: http://lattes.cnpq.br/2275102384879978. 